\title{
VARIAÇÃO MENSAL DA DEPOSIÇÃO DE SERAPILHEIRA EM POVOAMENTO DE Pinus taeda L. EM ÁREA DE CAMPO NATIVO EM CAMBARÁ DO SUL-RS ${ }^{1}$
}

\author{
Márcio Viera² e Mauro Valdir Schumacher²
}

\begin{abstract}
RESUMO - Objetivou-se com este trabalho avaliar a deposição de serapilheira em Pinus taeda L., implantado em área de campo nativo, durante um período de três anos ( $5^{\circ}$ ao $7^{\circ}$ ano de idade da floresta), no Município de Cambará do Sul, na região dos Campos de Cima da Serra, no Rio Grande do Sul. Foram alocadas quatro parcelas de $18 \mathrm{~m}$ x 50 m, de forma aleatória, e nelas foram distribuídos 20 coletores de serapilheira de 1 $\mathrm{m}^{2}$ (cinco em cada). A serapilheira interceptada nos coletores foi coletada mensalmente entre abril/2004 e março/2007. Após cada coleta, a serapilheira foi posta em estufa para secagem e determinação do peso de matéria seca. A deposição média anual de serapilheira foi de $2.545,1 \mathrm{~kg} \mathrm{ha}^{-1}$, tendo a seguinte ordem estacional média: outono > verão > inverno > primavera. A umidade relativa foi a única variável climática que apresentou correlação significativa $(r=0,365 ; p<0,05)$ com a deposição de serapilheira.
\end{abstract}

Palavras-chave: Serapilheira, Pinus e Campo nativo.

\section{MONTHLY VARIATION OF LITTER DEPOSITION IN PinUs taeda L. STAND IN NATIVE GRASS AREA IN CAMBARÁ DO SUL-RS}

\begin{abstract}
This study had as its objective to evaluate the litter deposition in Pinus taeda L. planted in native grass areas, during three years ( $5^{\circ}$ to $7^{\circ}$ year after forest planting), in Cambará do Sul, RS. Four plots with $18 \mathrm{~m} \times 50 \mathrm{~m}$ were randomly allocated and 20 litter collectors with $1 \mathrm{~m}^{2}$ were distributed in the plots (5 in each one). The litter was collected monthly between April /2004 and march/2007. After each collection, the litter was dried in an oven to determine the dried weight. The average annual litter deposition was 2,545.1 $\mathrm{kg} \mathrm{ha}^{-1}$, with the following seasonal order: autumn $>$ summer $>$ winter $>$ spring. The relative humidity was the only meteorological variable with significant correlation $(r=0.365 ; p<0.05)$.
\end{abstract}

Keywords: Litter, Pinus e Native grass.

\section{INTRODUÇÃO}

As diversas espécies de pinus plantadas nas Regiões Sul e Sudeste do Brasil são de introdução relativamente recente, por volta de 1954 , e visam à produção de madeira para abastecimento industrial, para processamento mecânico, na produção de madeira serrada, madeira laminada, na confecção de painéis ou na produção de celulose e papel, constituindo alternativa em substituição à madeira de Araucaria angustifolia, cujos povoamentos naturais se achavam em rápido processo de exaustão. Os plantios de pinus foram acelerados a partir de 1966, com a implantação da política de incentivos fiscais, em 1975, dos 459.000 hectares implantados no Estado de São Paulo, cerca de 190.000 hectares eram do gênero Pinus (KRONKA et al., 2005; MONTAGNA e YAMAZOC, 1978). Porém, para que a produção de madeira nesses plantios florestais se dê de forma sustentável, são necessários que sejam caracterizados os aspectos ecológicos das florestas, os quais permeiam os caminhos das sustentabilidades espacial e temporal. Entre os aspectos ecológicos relevantes, que devem ser estudados, destaca-se a ciclagem de nutrientes decorrente da deposição e decomposição da serapilheira dentro do ecossistema florestal.

Os principais mecanismos responsáveis pela transferência de nutrientes da biomassa de espécies arbóreas para o solo são: a deposição de serapilheira, a lavagem da vegetação pela chuva, que carrega substâncias minerais e orgânicas presas às estruturas

\footnotetext{
${ }^{1}$ Recebido em 01.03.2008 e aceito para publicação em 02.03.2010.

${ }^{2}$ Universidade Federal de Santa Maria, UFSM, Brasil. E-mail: <vieraflorestal@yahoo.com.br>.
} 
da parte aérea e a decomposição da biomassa morta, que inclui a serapilheira e raízes mortas (SANCHEZ, 1976; GONZALEZ e GALLARDO, 1986). Os fragmentos orgânicos, ao caírem sobre o solo, formam a camada denominada serapilheira (GOLLEY et al., 1978). A importância da serapilheira, para a ciclagem dos nutrientes em povoamentos florestais nativos ou implantados, é reconhecida desde o século passado (PRITCHETT, 1979).

A serapilheira constitui-se na camada de detritos vegetais (folhas, ramos, caules, cascas, frutos e flores) e animais disposta na superfície do solo. Sua formação se reflete no equilíbrio entre a produção e a decomposição no sistema (OLSON, 1963). Ela contribui, juntamente com os demais compartimentos florestais, para a interceptação da água da chuva, por meio do amortecimento e da consequente dispersão da energia cinética das gotas, minimizando, assim, os efeitos erosivos. Através de gradiente vertical de decomposição, a camada de serapilheira contribui para o armazenamento de água no solo, bem com o aumento das taxas de infiltração e condicionamento dos fluxos superficiais (OLIVEIRA FILHO, 1987).

Essa camada, juntamente com a parte aérea e radicular das plantas, protege o solo dos agentes desagregadores e propicia condições para o restabelecimento de suas propriedades físicas, químicas e biológicas (ANDRADE et al., 2000). Além do mais, com a permanência da serapilheira no local em contato com o solo esta pode ser reaproveitada no ciclo de nutrientes. A importância desse ciclo que se forma entre a comunidade viva e o seu meio é evidenciada quando se nota que muitas florestas se mantêm em áreas com solos de baixa fertilidade e incapazes de suportar outras culturas.

Galvão et al. (1991) comentaram em seu estudo que a quantidade de serapilheira disponível para a decomposição sobre o solo aumenta à medida que as comunidades vegetais se desenvolvem, atravessando diversas etapas num processo contínuo e caracterizado por mudanças na flora, na fauna, no solo e no microclima de uma comunidade vegetal.

Com base nesses pressupostos, objetivou com este trabalho estimar a quantidade de serapilheira depositada num povoamento de Pinus taeda L. implantado em área de campo nativo, durante um período de três anos ( $5^{\circ}$ ao $7^{\circ}$ ano de idade), em Cambará do Sul, RS.

\section{MATERIAL E MÉTODOS}

\subsection{Descrição da área de estudo}

O experimento foi realizado em um povoamento de Pinus taeda L., em área pertencente à empresa Reflorestadores Unidos, na cidade de Cambará do Sul, RS. Estando situado nas coordenadas geográficas de $29^{\circ} 10^{\prime}$ de latitude sul e $50^{\circ} 19^{\prime}$ de longitude oeste, numa altitude média de $893 \mathrm{~m}$. A cidade de Cambará do Sul localiza-se no nordeste do Estado do Rio Grande do Sul, na região fisiográfica dos Campos de Cima da Serra.

Segundo a classificação climática de Köppen, o tipo de clima fundamental predominante é o Cfb (temperado úmido), e a precipitação média na região é de $1.700 \mathrm{~mm}$, bem distribuída durante o ano. A temperatura média anual é de aproximadamente $15^{\circ} \mathrm{C}$, sendo que a média das temperaturas máximas de $22^{\circ} \mathrm{C}$ e a média das temperaturas mínimas, de 8,5ㄷ (MORENO, 1961).

Conforme Motta et al. (1971), os ventos dominantes na região são alísios, ou seja, sopram do mar para a terra, devido ao fato de a região situar-se próximo ao litoral norte do estado do Rio Grande do Sul.

Quanto ao solo, o material de origem é rocha basáltica, resultante do derrame basáltico do Triássico Superior, predominando solos rasos com horizonte A de coloração escura, com baixa saturação de bases e teor elevado de alumínio trocável (BRASIL, 1973). O solo da região pertence à Unidade de Mapeamento Bom Jesus, sendo classificado como Cambissolo Húmico alumínico típico (STRECK et al., 2002).

O povoamento de $P$. taeda, deste estudo foi implantado em área de campo nativo, após preparo mínimo de solo com escarificação na linha de plantio, atingindo uma profundidade média de $30 \mathrm{~cm}$. O plantio do povoamento aconteceu no período de inverno do ano de 1999, com mudas clonais produzidas em tubetes e optando-se por um espaçamento de $3 \mathrm{~m}$ x $2 \mathrm{~m}$. Por ocasião do plantio não foi realizado nenhum tipo de adubação. Não se efetuaram manutenções no plantio, (controle de matocompetição e de pragas). Aos 4 anos de idade, as árvores sofreram poda (desrama) até 2,5 metros de altura. 


\subsection{Metodologia do estudo}

Em condições de sítio semelhantes foram alocadas, de forma aleatória (SOARES et al., 2006), 4 parcelas de $18 \mathrm{~m}$ x $50 \mathrm{~m}$. Foram distribuídos 20 coletores de serapilheira, cinco em cada parcela. A alocação destes coletores no interior da parcela (Figura 1) procedeu-se da seguinte maneira: 2 na linha de plantio, 2 na entrelinha de plantio e 1 na diagonal entre duas linhas de plantio. Os coletores são do tipo bandeja, dispostos a 0,70 m de altura do solo, com uma área de coleta de $1 \mathrm{~m}^{2}$ cada.

Mensalmente, coletou-se o material interceptado nos coletores, durante um período de três anos (abril de 2004 a março de 2007). O material recolhido foi acondicionado em embalagem plástica, devidamente identificado e enviado ao Laboratório de Ecologia Florestal, pertencente ao Departamento de Ciências Florestais da Universidade Federal de Santa Maria.

No laboratório, as amostras foram secas em estufa de circulação e renovação de ar a $70^{\circ} \mathrm{C}$, por um período de $72 \mathrm{~h}$, sendo posteriormente pesado em balança digital de precisão $(0,01 \mathrm{~g})$.

A partir dos dados provenientes da coleta mensal de serapilheira, foi estimada a quantidade total de matéria seca (serapilheira) depositada sob o piso florestal. Para a análise de correlação de PEARSON (r), entre a deposição de serapilheira e variáveis climáticas e para a comparação das médias através do teste de Tukey, ambos a 5\% de probabilidade de erro, utilizou-se o software SPSS

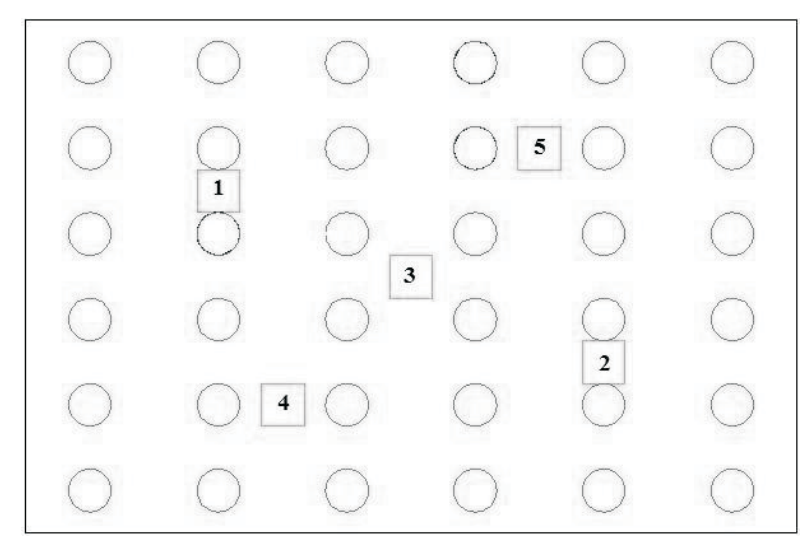

Figura 1 - Esquema demonstrativo da distribuição dos coletores de serapilheira no interior do povoamento de Pinus taeda L., em Cambará do Sul-RS.

Figure 1-Demonstrative scheme for litter collectors in the Pinus taeda stand in Cambará do Sul-RS.
7.5.1 for Windows (1996). Para a comparação de médias, consideraram-se os meses do ano como tratamentos e o número de parcelas (quatro) as repetições.

Os dados climáticos são provenientes da estação meteorológica do $8^{\circ}$ Distrito de Meteorologia do Instituto Nacional de Meteorologia, localizada no Município de Cambará do Sul-RS, próxima à área de pesquisa.

\section{RESULTADOS}

A deposição média anual de serapilheira alcançou 2,55 $\mathrm{Mg} \mathrm{ha}^{-1}$ (Tabela 1). A deposição aumentou com o passar dos anos, sendo de 2,13; 2,74 e 2,76 $\mathrm{Mg} \mathrm{ha}^{-}$ ${ }^{1}$, para os anos 1,2 e 3 , respectivamente, não havendo diferença significativa ( $p>0,05)$ entre os 3 anos de avaliação.

Na relação geral, os meses que mais influenciaram na deposição de serapilheira foram abril e junho no ano 1 (abr/04-mar/05), março e julho no ano 2 (abr/05-mar/06) e abril e março no ano 3 (abr/06-mar/07), com 30,1; 29,9; e $24,1 \%$ do total, respectivamente. Já o período de menor deposição foi igual em todos os anos, ocorrendo no mês de outubro.

Quanto à variação estacional da deposição de serapilheira, no primeiro ano ela foi da seguinte maneira: outono>verão>primavera>inverno; no ano 2, a magnitude foi: verão $>$ outono $>$ inverno $>$ primavera. já no ultimo ano foi: outono>verão>inverno>primavera. Em relação à média anual estacional, a deposição na estação outono foi maior, não diferindo estatisticamente ( $p>0,05)$ em relação ao verão e inverno; já na primavera a deposição foi significativamente inferior $(\mathrm{p}<0,05)$ ao período outonal.

Nas Figuras 2, 3 e 4, observam a variação da deposição mensal de serapilheira, a pluviosidade e a temperatura média do ar na região de estudo, durante os três anos de observações. Com a diminuição da pluviosidade, verificou-se que aumento na deposição de serapilheira, em todo o período de estudo. O contrário acontece com a temperatura média do ar, a qual, quando está em elevação, aumenta a taxa de deposição.

O coeficiente de correlação de PEARSON (r) encontrado entre a deposição média anual de serapilheira e a temperatura média do ar foi igual a 0,101 ( $>>0,05)$; para a pluviosidade foi de -0,044 ( $>>0,05)$, já a correlação com a umidade relativa do ar foi de $0,365(p<0,05)$, sendo apenas a última significativa.

Revista Árvore, Viçosa-MG, v.34, n.3, p.487-494, 2010 
Tabela 1 - Deposição mensal de serapilheira $\left(\mathrm{kg} \mathrm{ha}^{-1}\right)$ no período de abril/2004 a março/2007, em um povoamento de $P$. taeda, em Cambará do Sul-RS

Table 1 - Monthly litter deposition (kg ha-1) from April/2004 to March/2007, in a P. taeda stand, Cambará do Sul-RS.

\begin{tabular}{|c|c|c|c|c|c|}
\hline Mês & $04-05^{1}$ & $05-06$ & $06-07$ & Média & Total \\
\hline Abril & $319,3 \mathrm{a}^{2}(15,0)^{3}$ & 284,8 abc $(10,4)$ & 352,9 а $(12,8)$ & $319,0( \pm 34,1)$ & $956,9(12,5)$ \\
\hline Maio & 193,2 abc $(9,1)$ & 263,9 abc $(9,6)$ & 191,3 ab $(6,9)$ & $216,1( \pm 41,4)$ & $648,4(8,5)$ \\
\hline Junho & 322,3 ab $(15,1)$ & 268,6 abc $(9,8)$ & 295,4 ab $(10,7)$ & $295,4( \pm 26,9)$ & $886,3(11,6)$ \\
\hline Julho & 145,5 вс $(6,8)$ & 367,6 ab $(13,4)$ & 251,2 ab $(9,1)$ & $254,8( \pm 111,1)$ & $764,3(10,0)$ \\
\hline Agosto & 111,4 с $(5,2)$ & 141,5 bc $(5,2)$ & 169,7 ab $(6,1)$ & $140,8( \pm 29,2)$ & $422,5(5,5)$ \\
\hline Setembro & 109,6 с $(5,1)$ & 284,1 abc $(10,4)$ & 227,8 ab $(8,2)$ & $207,2( \pm 89,1)$ & $621,5(8,1)$ \\
\hline Outubro & 63,2 с $(3,0)$ & 50,4 с $(1,8)$ & 88,3 с $(3,2)$ & $67,3( \pm 19,3)$ & $201,9(2,6)$ \\
\hline Novembro & 138,5 с $(6,5)$ & 58,8 с $(2,1)$ & 184,8 ab $(6,7)$ & $127,4( \pm 63,7)$ & $382,1(5,0)$ \\
\hline Dezembro & 175,1 abc $(8,2)$ & 113,1 bс $(4,1)$ & 178,0 ab $(6,4)$ & $155,4( \pm 36,7)$ & $466,2(6,1)$ \\
\hline Janeiro & 197,9 abc $(9,3)$ & 210,2 abc $(7,7)$ & 253,8 ab $(9,2)$ & $220,6( \pm 29,3)$ & $661,9(8,7)$ \\
\hline Fevereiro & 154,5 abc $(7,3)$ & 245,9 abc $(9,0)$ & 258,4 ab $(9,4)$ & $219,6( \pm 56,7)$ & $658,8(8,6)$ \\
\hline Março & 200,8 abc $(9,4)$ & 452,0 a $(16,5)$ & 311,6 ab $(11,3)$ & $321,5( \pm 125,9)$ & $964,4(12,6)$ \\
\hline Total & $2131,3(100,0)$ & $2740,8(100,0)$ & $2763,1(100,0)$ & $2545,1( \pm 358,5)$ & $7635,2(100,0)$ \\
\hline $\mathrm{CV} \%{ }^{4}$ & 44,1 & 52,9 & 31,5 & 37,3 & \\
\hline
\end{tabular}

${ }^{1} 04$ - 05 (correspondem ao período de abril/2004 a março/2005); 05 - 06 (abril/2005 a março/2006) e 06 - 07 (abril/2006 a março/2007). ${ }^{2}$ Valores na vertical seguidos pela mesma letra não diferem entre si, pelo teste de Tukey a 5\% de probabilidade de erro. ${ }^{3}$ Valores entre parênteses referem-se à porcentagem de cada mês em relação ao total de serapilheira depositada naquele ano, e a média refere-se aos desvios-padrão. ${ }^{4}$ Coeficiente de variação experimental percentual anual.

\section{DISCUSSÃO}

A deposição de serapilheira encontrada neste estudo foi inferior a de outros trabalhos encontrados na literatura. Em um povoamento de Pinus taeda L. de segunda rotação, na região de Cambará do Sul,RS, com 6 anos de idade, Viera et al. (2006) encontraram uma deposição de aproximadamente 4,0 $\mathrm{Mg} \mathrm{ha}^{-1}$. Poggiani et al. (1987), na mesma espécie aos 7-9 anos de idade no Município de São Mateus do Sul,PR, encontraram uma deposição média anual de 4,4 $\mathrm{Mg} \mathrm{ha}^{-1}$.

Em plantios de Pinus taeda com 15 anos de idade, na região de Ponta Grossa,PR, Koehler (1989), analisando três sítios diferentes, encontrou deposição média anual de 8,7 $\mathrm{Mg} \mathrm{ha}^{-1}$ no sítio bom, $8,4 \mathrm{Mg} \mathrm{ha}^{-1}$ no sítio médio e $6,5 \mathrm{Mg} \mathrm{ha}^{-1}$ no sítio ruim.

No estudo realizado por Poggiani (1985), com ciclagem de nutrientes em ecossistemas de plantações florestais de eucaliptos com 7 anos de idade e pinus com 11 anos de idade, o citado autor encontrou deposição de 4,5 $\mathrm{Mgha}^{-1} \mathrm{em}$ Eucalyptus saligna, 7,1 $\mathrm{Mg} \mathrm{ha}^{-1}$ em Pinus oocarpa e 8,4 $\mathrm{Mg} \mathrm{ha}^{-1}$ em Pinus caribaea var. hondunensis.

Melo e Resck(2002), estudando diferentes procedências de pinus com 16 anos de idade, implantados na região do Cerrado, encontraram deposição anual de 9,9 e 9,2 $\mathrm{Mgha}^{-1}$, em Pinus caribaea var. bahamensis e 6,7 $\mathrm{Mg} \mathrm{ha}^{-1}$ no povoamento de Pinus caribaea var. hondurensis.
As diferenças de deposição podem ser atribuídas a vários fatores como: diferentes características genéticas de cada espécie utilizada, tipo de sítio, idade do povoamento, densidade de plantio, características edafoclimáticas e estabilidade alcançada pelo povoamento, dentre outros (SCHUMACHER e POGIANI, 2000; FIGUEIREDO FILHO et al., 2003; MOREIRA e SILVA, 2004; FERNANDES et al., 2007).

Para Bray e Gorham (1964), a quantidade de material orgânico depositado ao longo de um ano depende, principalmente, das condições climáticas, sendo menores nas regiões frias, e maiores nas regiões equatoriais quentes e úmidas. Florestas situadas em regiões árticas ou alpinas produzem, anualmente, cerca de uma tonelada por hectare de serapilheira, florestas temperadas frias 3,5 toneladas, florestas temperadas quentes 5,5 toneladas e florestas equatoriais cerca de 11 toneladas.

O povoamento apresentou magnitude estacional média de deposição, seguindo a ordem: outono > verão $>$ inverno > primavera. Sendo ela variável em cada ano de observação, não estando bem definida em razão, provavelmente, da juvenilidade das plantas, as quais ainda não atingiram padrão fenológico de perda (troca) de folhagem ou, também, podendo estar atrelada a atipicidades climáticas.

Essa maior produção no outono e menor no período inverno-primavera éa mesma encontrada por Koehler (1989) em povoamentos de Pinus taeda, na região de Ponta 
Grossa,PR, e por Viera et al. (2006) com a mesma espécie na região de Cambará do Sul,RS. Segundo Schumacher (1992), nas florestas localizadas em regiões de clima temperado a chegada do outono é o fenômeno que desencadeia o processo de derrubada natural das folhas.

Os picos de deposição de serapilheira ocorridos em abril e junho no ano 1 (Figura 2) devem-se, provavelmente, à baixa precipitação nesses períodos, podendo-se considerar que ocorreu baixa disponibilidade hídrica. Com isso, houve elevação da perda de folhagem como estratégia de sobrevivência das plantas, diminuindo, dessa maneira, a perda de água através da transpiração.

Já os maiores valores de deposição ocorridos em julho e setembro e a contínua elevação a partir de novembro do ano 2 (Figura 3) também estão relacionados com disponibilidade de água para as plantas, além do mais, em outubro iniciou-se a elevação da temperatura que poderia contribuir com maior deposição (estratégia de sobrevivência), devido ao fato de ela provocar maior transpiração das plantas.

Na Figura 4, observa-se mesma tendência que nos anos anteriores. Deve-se ressaltar que alguns desses picos de deposição, ocorridos durante o período de estudo, podem estar relacionados a fatores climáticos extremos, como ventos intensos e períodos de alta umidade que ocasionariam acelerado processo de perda de folhagem senescente pelas plantas.

Estudos realizados por Ferreira et al. (2007), Moreira e Silva (2004), Souto (2006), Melo e Resck (2002) e Mochiutti et al. (2006) concluíram que as maiores deposições de serapilheira poderiam estar relacionadas

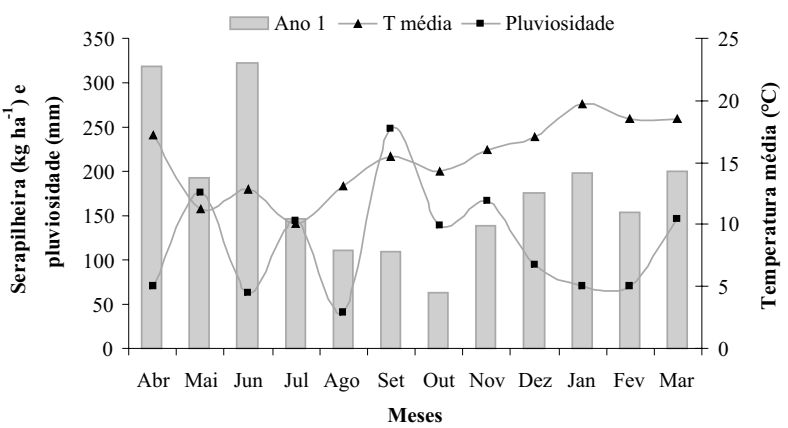

Figura 2 - Acúmulo mensal de serapilheira $\left(\mathrm{kg} \mathrm{ha}^{-1}\right)$, pluviosidade $(\mathrm{mm})$ e temperatura média do ar $\left({ }^{\circ} \mathrm{C}\right)$, no período de abr./2004 a mar./2005.

Figure 2 - Figure 2 - Monthly litter accumulation $\left(\mathrm{kg} \mathrm{ha}^{-1}\right)$, rainfall $(\mathrm{mm})$ and mean temperature $\left({ }^{\circ} \mathrm{C}\right)$ from April/2004 to March/2005. com a menor pluviosidade ocorrida em alguns meses do ano (período seco). No estudo realizado por Andrade et al. (2000) com leguminosas arbóreas, as maiores taxas de deposição mensal ocorreram no período de fevereiro a junho (o mesmo deste estudo), período em que ocorreu diminuição da pluviosidade e da temperatura, o que poderia estimular as plantas a aumentar a queda de material senescente. Dias et al. (2002) comentaram ainda que o estresse hídrico desencadeia uma série de eventos fisiológicos na planta, acarretando, no final, a abscisão das folhas.

Já os autores Bray e Gorham (1964) comentaram que, além da deficiência hídrica, a diminuição do fotoperíodo está seguidamente influenciando a maior deposição de serapilheira. Para Brun et al. (2001), a temperatura influencia de maneira mais marcante a deposição, de forma que as maiores quedas de serapilheira ocorrem nos meses de temperatura elevada.

Dias et al. (2002) e Oliveira Filho (1987) consideraram que a maior produção de serapilheira nos meses mais frios e secos do ano seria uma característica típica de florestas tropicais estacionais e, ao contrário, maior deposição na transição entre estação seca e chuvosa seria típico de regiões tropicais e subtropicais.

Segundo Poggiani (1985), a derrubada mais intensa de acículas estaria relacionada com períodos em que a umidade do solo se torna muito baixa. Autores como Gisler (1995) e Martins e Rodrigues (1999) sugeriram que o estresse hídrico seja uma causa da queda sazonal de material de árvores em muitas florestas.

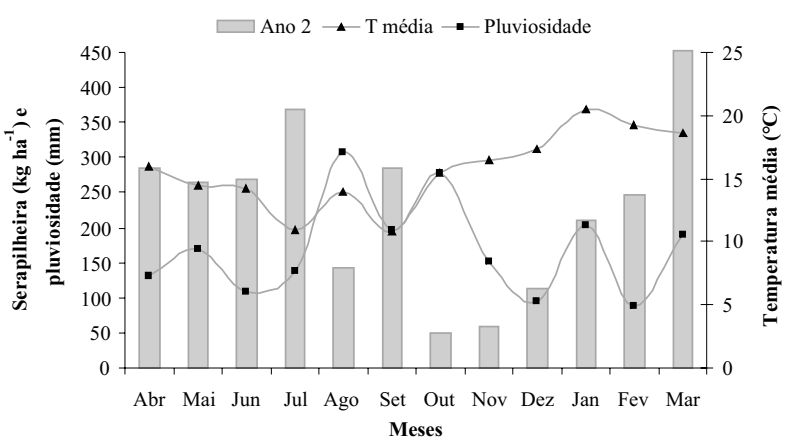

Figura 3 - Acúmulo mensal de serapilheira $\left(\mathrm{kg} \mathrm{ha}^{-1}\right)$, pluviosidade $(\mathrm{mm})$ e temperatura média do $\operatorname{ar}\left({ }^{\circ} \mathrm{C}\right)$, no período de abr./2005 a mar./2006.

Figure 3 - Monthly litter accumulation $\left(\mathrm{kg} \mathrm{ha}^{-1}\right)$, rainfall ( $\mathrm{mm}$ ) and mean temperature $\left({ }^{\circ} \mathrm{C}\right)$ from April/ 2005 to March/2006.

Revista Árvore, Viçosa-MG, v.34, n.3, p.487-494, 2010 


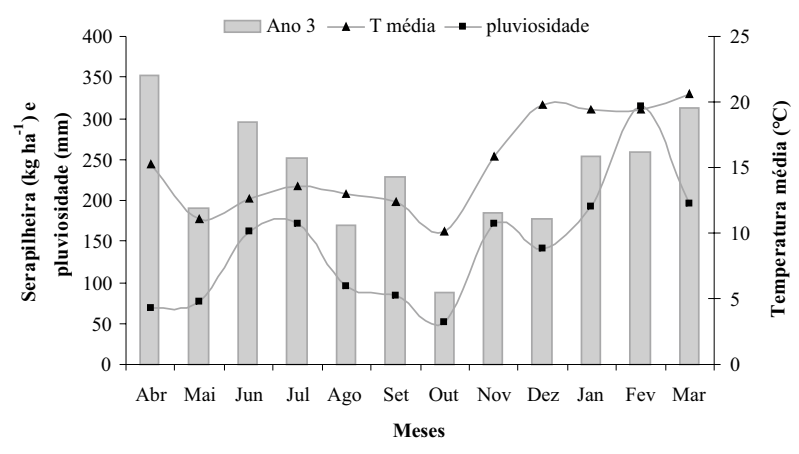

Figura 4 - Acúmulo mensal de serapilheira $\left(\mathrm{kg} \mathrm{ha}^{-1}\right)$, pluviosidade $(\mathrm{mm})$ e temperatura média do $\operatorname{ar}\left({ }^{\circ} \mathrm{C}\right)$, no período de abr./2006 a mar./2007.

Figure 4 - Monthly litter accumulation $\left(\mathrm{kg} \mathrm{ha}^{-1}\right)$, rainfall $(\mathrm{mm})$ and mean temperature $\left({ }^{\circ} \mathrm{C}\right)$ from April/ 2006 to March/2007.

Com base na correlação de PEARSON (r), apenas a umidade relativa do ar apresentou correlações significativa $(\mathrm{p}<0,05)$ e positiva com a deposição de serapilheira. Mesmo com os picos de deposição ocorridos com os períodos de baixa pluviosidade não ocorreu correlação significativa, e isso se deve, em parte, à irregularidade dos regimes de chuva. A correlação entre a deposição de serapilheira e a umidade relativa do ar também foi encontrada por Koehler (1989), em povoamentos da mesma espécie.

\section{CONCLUSÃO}

A deposição média anual de serapilheira encontrada foi de 2,5 $\mathrm{Mg} \mathrm{ha}^{-1}$, sendo ela crescente, mas não significativamente, com o desenvolvimento do povoamento.

A deposição é maior no período verão-outono e menor no inverno-primavera.

A umidade relativa do ar foi a única variável climática que apresentou correlação significativa com a deposição $(r=0,365 ; p<0,05)$.

\section{AGRADECIMENTOS}

Ao Conselho Nacional de Desenvolvimento Científico e Tecnológico (CNPq), pela bolsa de iniciação científica concedida ao primeiro autor; à empresa Reflorestadores Unidos S/A, pela manutenção da área experimental, coleta, envio de amostras e auxilio logístico; e aos dois pareceristas anônimos, pelas sugestões e pelos questionamentos, os quais foram muito bem aceitos, melhorando a qualidade deste artigo.

\section{REFERÊNCIAS}

ANDRADE, A. G. et al. Deposição e decomposição da serapilheira em povoamentos de Mimosa caesalpiniifolia, Acacia manguim e Acacia holosericea com quatro anos de idade em planossolo. Revista Brasileira de Ciência do Solo, v.24, n.3, p.777-785, 2000.

BRASIL. Ministério da Agricultura. Divisão de Pesquisa Pedológica DNPEA. Levantamento de reconhecimento dos solos do Estado do Rio Grande do Sul. Recife: 1973. 431p. (Boletim Técnico, 30).

BRAY, J. R.; GHORAN, E. Litter production in forest of the world. Advances in Ecological Research., v.2, n.1, p.101-157, 1964.

BRUN, E. J. et al. Relação entre a produção de serapilheira e variáveis meteorológicas em três fases sucessionais de uma floresta Estacioanal Decidual no Rio Grande do sul. Revista Brasileira Agrometeorologia, v.9, n.2, p.277-285, 2001.

DIAS, H. C. T. et al. Variação temporal de nutrientes na serapilheira de um fragmento de floresta estacional semidecidual em Lavras, Minas Gerais - Brasil. Cerne, v.8, n.2, p.1-16, 2002.

FERREIRA, R. L. C. Deposição e acúmulo de matéria seca e nutrientes em serapilheira em um bosque de sabiá (Mimosa caesalpiniifolia Benth). Revista Árvore, v.31, n.1, p.7-12, 2007.

FERNANDES, M. E. B.; NASCIMENTO, A. A. M.; CARVALHO, M. L. Estimativa da produção anual de serapilheira dos bosques de mangue no Furo Grande, Bragança-Pará. Revista Árvore, v.31, n.5, p.949-958, 2007.

FIGUEIREDO FILHO, A. et al. Avaliação estacional da deposição de serapilheira em uma Floresta Ombrófila Mista localizada no sul do estado do Paraná. Ciência Florestal, v.13, n.1, p.11-18, 2003.

GALVÃO, F.; ZILLER, S. R.; BUFREM, A. M. Decomposição foloiar de algumas espécies arbóreas: análise sucessional em floresta estacional decidual. Revista Setor de Ciências Agrárias, v.11, n.1-2, p.161-168, 1991. 
GISLER, C. V. T. O uso da serapilheira na recomposição da cobertura vegetal em áreas mineradas de bauxita, Poços de Caldas, MG. 1995. 146f. Dissertação

(Mestrado em Ecologia) - Universidade de São Paulo, Instituto de Biociências, São Paulo, 1995.

GOLLEY, F. B. et al. Ciclagem de minerais em um ecossistema de Floresta Tropical Úmida. Tradução de Eurípedes Malavolta. São Paulo: EPU, 1978. 256p.

GONZÁLEZ, M. I. M.; GALLARDO, J. F. El efecto hojarasca: una revisión. Anales de

Adafología y Agrobiología, v.41, n.6, p.1130-1157, 1986.

KOEHLER, W. C. Variação estacional de deposição de serapilheira e de nutrientes em povoamentos de Pinus taeda na região de Ponta Grossa-PR. 1989. 138f. Tese (Doutorado em Ciências Florestais) - Universidade Federal de Paraná, Curitiba, 1989.

KRONKA, F. J. N.; BERTOLANI, F.; PONCE, R. H. A cultura do Pinus no Brasil. São Paulo: Sociedade Brasileira de Silvicultura, 2005. 160p.

MARTINS, S. V.; RODRIGUES, R. R. Produção de serapilheira em clareiras de uma floresta estacional semidecidual no município de Campinas, S. P. Revista Brasileira de Botânica, v.22, n.3, p.405-412, 1999.

MELO, J. T.; RESCK, D. V. S. Retorno, ao solo, de nutrientes de serapilheira de Pinus no cerrado do Distrito Federal.

Planantina: Embrapa Cerrados, 2002. 18p. (Boletim de Pesquisa e Desenvolvimento/Embrapa Cerrados, 75).

MOCHIUTTI, S.; QUEIROZ, J. A. L.; MELÉM JUNIOR, N. J. Produção de serapilheira e retorno de nutrientes de um povoamento de táxi-branco e de uma Floresta Secundária no Amapá. Boletim de Pesquisa Florestal, n.52, p.3-20, 2006.

MONTAGNA, R. G.; YAMAZOC, G. Utilização de madeira de pequenas dimensões. Silvicultura, v.2, n.14, p.78-179, 1978.

MOREIRA, P. R.; SILVA, O. A. Produção de serapilheira em área reflorestada. Revista Árvore, v.28, n.1, p.49-59, 2004.
MORENO, J. A. Clima do Rio Grande do Sul. Porto Alegre: Secretaria da Agricultura, 1961. 41p.

MOTTA, F. S.; BEISDORF, M. J. C.; GARCEZ, R. $B$. Zoneamento agrícola do Rio Grande do Sul e Santa Catarina: normas agro-climáticas. Pelotas: Ministério da Agricultura, 1971. 80p.

OLIVEIRA FILHO, R. R. Produção e decomposição de serapilheira no Parque Nacional da Tijuca, RJ. 1987. 107f. Dissertação (Mestrado em Geografia) Instituto de Geociências, Rio de Janeiro, 1987.

OLSON, J. S. Energy storage and the balance of producers and decomposers in ecological systems. Ecology, v.44, n.2, p.322-330, 1963.

POGGIANI, F. Ciclagem de nutrientes em ecossistemas de plantações florestais de Eucalyptus e Pinus: implicações silviculturais. 1985. 229f. Tese (Livre Docência) - Escola Superior de Agricultura Luiz de Queiroz, Piracicaba, 1985.

POGGIANI, F. et al. Quantificação da deposição de folhedo em talhões experimentais de Pinus taeda, Eucalyptus viminalis e Mimosa scabrella plantados em uma área degradada pela mineração do xisto betuminoso. IPEF, v.47, p.21-29, 1987.

PRITCheTT, W. L. Properties and management of forest soils. New York: John Wiley, 1979. 500p.

SANCHEZ, P. A. Properties and management of soils in the tropics. New York: John Wiley \& Sons, 1976. 409p.

SCHUMACHER, M. V.; POGGIANI, F. Ciclagem de nutrientes em florestas nativas. In: GONÇALVES, J. L.; BENEDETTI, V. (Eds.) Nutrição e fertilização florestal. Piracicaba: IPEF, 2000. p.285-306.

SCHUMACHER, M.V. Aspectos da ciclagem de nutrientes e do microclima em talhões de Eucalyptus camaldulensis Dehnh, Eucalyptus grandis Hill ex Maiden e Eucalyptus torrelliana F. Mesell. 1992. 87f. Dissertação (Mestrado em Engenharia Florestal) Escola Superior de Agricultura "Luiz de Queiroz" Universidade de São Paulo, Piracicaba 1992.

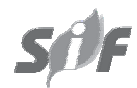


SOARES, C. P. B.; NETO, F. P.; SOUZA, A. L.

Dendrometria e Inventário Florestal. Viçosa,MG: Universidade Federal de Viçosa, 2006. 276p.

SOUTO, P. C. Acumulação e decomposição da serapilheira e distribuição de organismos edáficos em área de Caatinga na Paraíba, Brasil. 2006. 150f. Tese (Doutorado em Agronomia) - Centro de Ciências Agrárias da Universidade Federal da Paraíba, Areia, 2006.
STATISTICAL PACKAGE FOR THE SOCIAL SCIENCES - SPSS. Programa de Computador, Ambiente Windows. Chicago: 1996. Versão 7.5.1.

STRECK, E. V. et al. Solos do Rio Grande do Sul. 2.ed. Porto Alegre: Emater/RS, 2008. 222p.

VIERA M. et al. Deposição de serapilheira em um povoamento de Pinus taeda L. no estado do Rio Grande do Sul. In: SIMPÓSIO DE PÓS-GRADUAÇÃO EM CIÊNCIAS FLORESTAIS, 4., 2006, Piracicaba. Anais... Piracicaba: ESALQ, 2006. 